\title{
When a definition makes the difference: operative issues about tree height measures from RPAS-derived CHMs
}

\author{
Samuele De Petris, \\ Roberta Berretti, \\ Filippo Sarvia, \\ Enrico Borgogno Mondino
}

\begin{abstract}
Tree height $(\mathrm{H})$ survey is a fundamental step in forest mensuration. The error affecting tree height measure, necessarily influences the correspondent tree estimates. The remotely survey of vegetation using PHODAR (PHOtogrammetric Detection And Ranging) or LiDAR (Light Detection And Ranging) techniques generates very high-density point clouds, that result into Canopy Height Models (CHMs) having GSD (Ground Sampling Distance) of few centimetres. This GSD value potentially allows to survey single crown apexes, which, from a forestry point of view, do not represent the actual tree height. Apex height value, in fact, does not represent the prevailing dendrometric height (PDH) but the maximum tree value. In this study we propose a new approach aimed at measuring dendrometric height by PHODAR derived $\mathrm{CHM}$, taking care about this issue. The proposed method defines a correcting factor (found equal to 95\% percentile of CHM values distribution within a given crown) for the tree height extraction from CHM based on the PDH concept. The method could be implemented to single crown approach in forest parameters extraction algorithms permitting more reliable results, especially in terms of tree volume and related estimations (e.g., carbon stock quantification, allometric models).
\end{abstract}

\section{Keywords: Tree Height, Prevailing Dendrometric Height, CHM, PHODAR, LiDAR} \& Akça 2007, West 2009), where angle and distance measures are coupled within simple trigonometric formulas. $\mathrm{H}$ is obtained by collimating the top and the basis of trees determining the correspondent angle and the horizontal distance separating observer and tree. This method suffers from different errors mainly related to the collimation process. Bragg (2014) found that errors mainly depend on the wrong detection of tree tops and stem inclination. An-

$$
V=\left(\frac{\pi}{4} D B H^{2}\right) H \cdot f
$$

other error is related to the operator's hand motion during the collimation step that, in the most of cases, is operated with no fixed support. The uncertainty that this operational conditions can determine in angular measures is estimated to range between $\pm 0.5^{\circ}$ and $\pm 2^{\circ}$, determining $\mathrm{H}$ errors between $1 \%$ to $10 \%$ (Andersen et al. 2006). The introduction of RPAS (Remotely Piloted Aircraft System) have enriched the survey of vegetated surfaces (Borgogno height operates by hypsometer (Van Laar

$\square$ DISAFA - Department of agriculture, forest and food sciences, University of Torino, Largo P. Braccini 2, Grugliasco, TO (Italy)

@ Samuele De Petris (samuele.depetris@unito.it)

Received: Mar 23, 2020 - Accepted: Jun 24, 2020

Citation: De Petris S, Berretti R, Sarvia F, Borgogno Mondino E (2020). When a definition makes the difference: operative issues about tree height measures from RPAS-derived CHMs. iForest 13: 404-408. - doi: 10.3832/ifor3411-013 [online 2020-09-03]

Communicated by: Carlotta Ferrara
Mondino \& Gajetti 2017). RPAS-based acquisitions can provide information about surfaces with a very high geometric resolution (Nevalainen et al. 2017, Jayathunga et al. 2018). Remote survey of vegetation can be operated by PHODAR (PHOtogrammetric Detection and Ranging) or LiDAR (Light Detection and Ranging) techniques. Both of them have largely improved the possibility of accurately measuring morphometric and structural parameters of forest stand or individual trees (Wang et al. 2004, Fritz et al. 2013, Lisein et al. 2013), thus supporting forest inventories. Many studies and practical experiences demonstrated that tree counting and tree height measure can be achieved with high accuracy (Wallace et al. 2012, 2014, Ni et al. 2015, Hassaan et al. 2016, De Petris et al. 2019). In this context, these parameters are derived by tree crown segmentation from Canopy Height Models (CHMs - Hyyppa et al. 2001, Jakubraster maps obtained by grid differencing between a Digital Surface Model (DSM) and Digital Terrain Model (DTM), possibly derived from point clouds. When trying to obtain tree measures from $\mathrm{CHM}$, the Local Maxima approach, applied within the same segment (representing the entire tree crown), is often used to locate the top of the tree (Andersen et al. 2006, Monnet et al. 2010, St-Onge et al. 2015). When working with high geometric resolution $\mathrm{CHMs}$, possibly obtained by PHODAR/LiDAR point clouds, the reference Ground Sampling Distance (GSD) sizes few centimeters. Such a value potentially allows to survey points owski et al. 2013, Yang et al. 2017), i.e., 


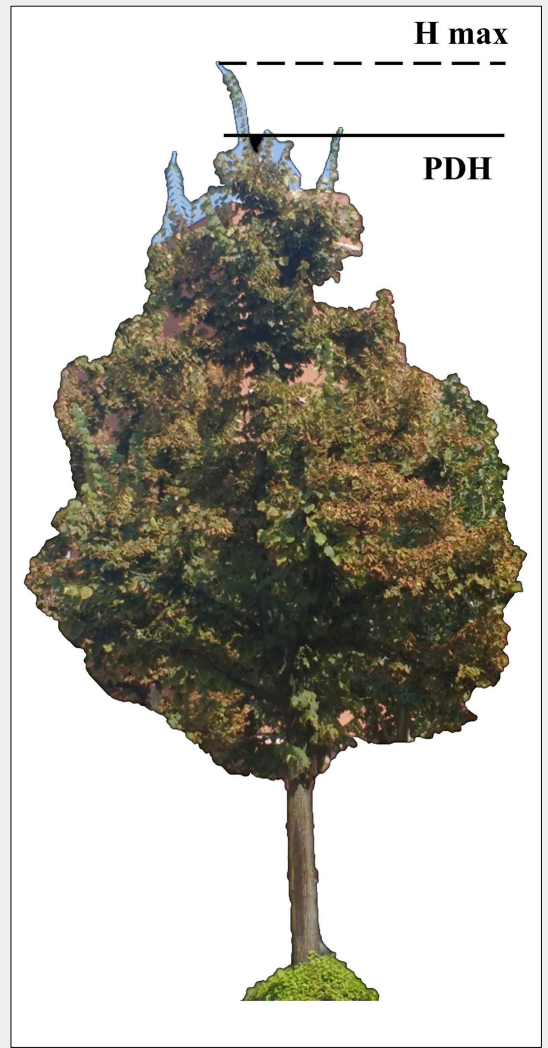

Fig. 1 - A new definition of prevailing dendrometric height (PDH) is proposed, corresponding to the most frequent height value occurring within upper tree crown.

representing single crown apexes that, according to the Local Maxima approach, can be labelled as the top when measuring tree height. Unfortunately, from a forestry point of view, apexes are not representatives of the actual tree height, since they do not represent the prevailing dendrometric height $\left(\mathrm{PDH}^{\mathrm{CHM}}\right)$ but, conversely, the maximum height value $\left(\mathrm{H}^{\mathrm{CHM}}\right.$ max - Fig. 1). Consequently, $\mathrm{H}^{\mathrm{CHM}}{ }_{\text {max }}$ could not be used to estimate tree volume or site indices, as a not negligible overestimation would occur. In this work, PDH is suggested to be newly defined as that height value corresponding to the most frequently one occurring within tree upper canopy.

\section{Materials and methods}

In this study, we propose a new definition of prevailing dendrometric height; consequently, a different approach, other than the Local Maxima one, has been considered to process CHM. A small and highly controllable CHM of 60 mixed broadleaf trees (Quercus robur L. 45\%, Fraxinus excelsior L. $12 \%$, Alnus glutinosa L. $7 \%$, Ulmus campestris Mill. 8\%, Robinia pseudoacacia L. $20 \%$, Tilia spp. $8 \%$ ) was processed. The study area is located in the "La Mandria" regional park (Piemonte, NW Italy). This study area was chosen for the presence of both ancient and young trees with different apexes length representing various ontological phases (Bond 2000). A ground survey was conducted to obtain a reference dataset. For each of the 60 surveyed trees the correspondent crown ground projection was mapped by Field-map ${ }^{\oplus}$ tools (Zambarda et al. 2010) and recorded as georeferenced vector layer P (Fig. 2). Tree height was measured by Vertex IV- $360^{\oplus}$ ul-

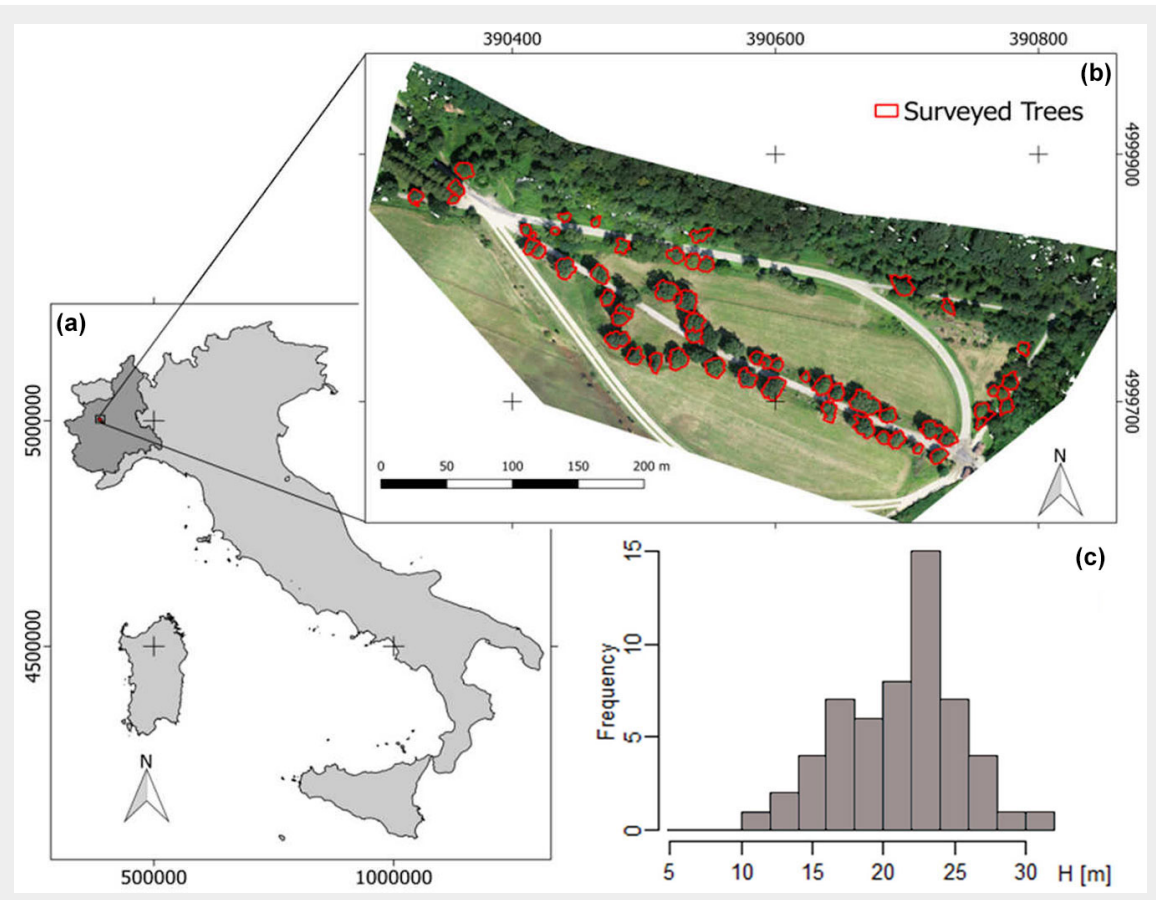

Fig. 2 - (a) Study area is located in "La Mandria" regional park (Piemonte - NW Italy); (b) RPAS-derived orthomosaic and surveyed tree crowns (reference frame is WGS84 UTM $32 \mathrm{~N}$ ); (c) Frequency distribution function of ground measured tree height $\left(\mathrm{H}_{\max }^{\mathrm{max}}\right)$.

Tab. 1 - Parameters of DJI Phantom4 RGB camera and flight parameters adopted for the photogrammetric survey.

\begin{tabular}{|c|c|c|}
\hline $\begin{array}{l}\text { Flight/Sensors } \\
\text { Parameters }\end{array}$ & Size & Units \\
\hline Focal length & 8.6 & $\mathrm{~mm}$ \\
\hline CMOS sensor size & $13.2 \times 8.8$ & $\mathrm{~mm}$ \\
\hline Physical pixel & 2.2 & $\mathrm{~mm}$ \\
\hline $\begin{array}{l}\text { Forward image } \\
\text { overlap }\end{array}$ & 93 & $\%$ \\
\hline Side image overlap & 83 & $\%$ \\
\hline $\begin{array}{l}\text { Flight relative } \\
\text { altitude (above } \\
\text { ground level) }\end{array}$ & 90 & $\mathrm{~m}$ \\
\hline
\end{tabular}

trasound hypsometer (Haglof, Sweden) at $40 \mathrm{~m}$ distance having a nominal accuracy of $\pm 0.25^{\circ}$ for angles and $\pm 0.2 \mathrm{~m}$ for distances. $\mathrm{H}^{\mathrm{G}}{ }_{\text {max }}$ was measured by collimating tree top (maximum visible height), while $\mathrm{PDH}^{\complement}$ was estimated with reference to the main development of the crown (i.e., pointing to the basis of the highest apexes). $\mathrm{H}_{\text {max }}$ and $\mathrm{PDH}^{\mathrm{C}}$ values were, finally, recorded into the attributes table of $\mathrm{P}$. The test $\mathrm{CHM}$ was generated by grid differencing between a DSM generated by regularization of a $\mathrm{PHO}$ DAR-derived point cloud surveyed by RPAS. A DJI Phantom4 RPAS equipped with a 12.4 Megapixel RGB camera was used for data acquisition. Flight and sensor's technical features are reported in Tab. 1. Obtained images (about 700) had a GSD of about $5 \mathrm{~cm}$. Photogrammetric block bundle adjustment and point cloud generation were achieved by the software Photo$\operatorname{scan}^{\circledast}$ v. 1.2.4 (Agisoft LLC, St. Petersburg, Russia). Image block bundle adjustment was achieved using 9 ground control points (GCPs) surveyed in correspondence of target panels (markers) distributed over the area before the flight. GCPs survey was achieved by VRS-NRTK (Virtual Reference Station - Network Real Time Kinematic) GNSS mode using a Leica $1200^{\circledR}$ receiver (3D positioning accuracy was $\sim 3 \mathrm{~cm}$ ). Leave-one-out procedure (Brovelli et al. 2008) was adopted to test bundle adjustment accuracy using the previous 9 GCPs without requiring additional survey and Mean Absolute Errors (MAE) were calculated. Point cloud was exported in .LAS format, filtered, classified as ground/notground, and regularized to generate the correspondent DSM (Digital Surface Model). Filtering, classifying and rasterizing processes were preformed using LAStools libraries (Isenburg 2012). CHM was computed by grid differencing between the above-mentioned DSM and an available DTM (Digital Terrain Model) obtained from the Piemonte Region geoportal (ICE dataset - http://www.geoportale.piemonte.it/g eocatalogorp/). DTM had a GSD $=5 \mathrm{~m}$ and a precision $\sigma_{z}{ }^{\mathrm{DTM}}=0.60 \mathrm{~cm}$ (Borgogno Mondi- 

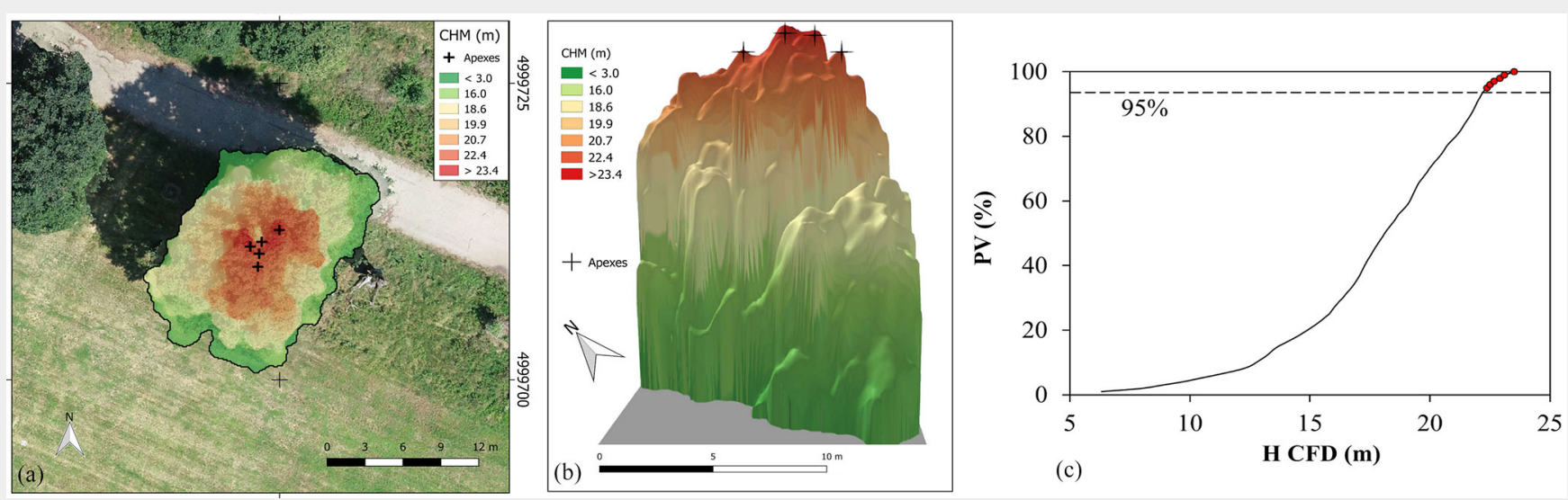

Fig. 3 - An example of oak crown in the study area. (a) CHM and apexes positions; (b) 3D view of CHM showing the role of outliers played by apexes within the crown; (c) H CFD of DC considered; dotted line represent the threshold value (95\% PV) used to filter out apexes (red dots).

no et al. 2016). DTM was oversampled by nearest neighbor method at $5 \mathrm{~cm}$ to make it consistent with the PHODAR derived DSM.

\section{Results and discussions}

The following positioning errors (MAE) were obtained for GCPs after image block adjustment adopting leave-one-out procedure: $0.267 \mathrm{~m}\left(\sigma_{x, y}\right), 0.229 \mathrm{~m}\left(\sigma_{z}\right)$ and 0.352 $\mathrm{m}\left(\sigma_{x, y, z}\right)$. A high-density point cloud was generated (about 36 million points, 250 pts $\mathrm{m}^{-2}$ ), filtered, classified and regularized to generate the correspondent DSM with a cell size of $0.1 \mathrm{~m}$. After regularization DSM height accuracy was tested with reference to the GCPs to exclude a degradation of the native accuracy. Results proved that height accuracy of DSM was the about same $\left(\sigma_{z}{ }^{\text {DSM }}=0.236 \mathrm{~m}\right)$ as the above mentioned one $\left(\sigma_{z}=0.229 \mathrm{~m}\right)$. CHM accuracy $\left(\sigma_{z}{ }^{\mathrm{CHM}}\right)$ was finally estimated by the Variance Propagation Law (VPL - Bevington \& Robinson 1974) involving $\sigma_{z}^{\text {DTM }}$ and $\sigma_{z}^{\text {DSM; }}$ $\sigma_{z}{ }^{\text {CHM }}$ resulted to be equal to $0.64 \mathrm{~m}$. Such accuracy is higher than that obtainable using hypsometer and adopted in ordinary forest inventory (Larsen et al. 1987). An object-based approach aimed at mapping tree crowns from CHM was used, adopting the watershed segmentation algorithms (available in SAGA GIS v. 7.4 - http://www. saga-gis.org/). The following parameters were used: segmentation criterion was the local minima one; joining segment threshold (minimum difference between neighbored segments) was set to 0.8. For each segment, assumed as tree crown perimeter (hereafter called Detected Crown $\mathrm{DC}$ ), the correspondent $\mathrm{CHM}$ zonal statistics (average, standard deviation, minimum and maximum) were computed and the cumulative frequency distribution of $\mathrm{H}(\mathrm{H}$ CFD) generated. H CFD was used as descriptor of the inter-crown variability and comparing tree CHM-based height with ground-based one. With reference to the above-mentioned H CFD (one for each of the segmented crowns) the percentile value (PV) correspondent to the local $\mathrm{PDH}^{\mathrm{C}}$ was computed. Sixty different PVs were found depending on the assessed crown. PV mean value $\left(\mu_{\mathrm{PV}}\right)$ was assumed as reference threshold, for broadleaves, to filter out apexes while measuring $\mathrm{PDH}^{\mathrm{CHM}}$ from CHMs. The computed $\mu_{\mathrm{PV}}$ value was $95 \%$; consequently, $\mathrm{PDH}^{\mathrm{CHM}}$ was found equal to the value within $D C$ which corresponds to the 95 percentile of H CFD (Fig. 3). In Fig. 4 the frequency distributions of $\mathrm{H}^{\mathrm{CHM}_{\max }}$ and $\mathrm{PDH}^{\mathrm{CHM}}$ are compared, figuring out the effect on tree height measure given assuming $\mathrm{PDH}^{\mathrm{CHM}}$ in place of $\mathrm{H}^{\mathrm{CHM}}$ max. The Kolmogorov-Smirnov test was run to test significance the similarity of the two distributions with a normal one. D-value was 0.075 $(p=0.871$, Skewness: 0.046$)$ and $0.069(p=$ 0.957, Skewness: 0.020 ) for $\mathrm{PDH}^{\mathrm{CHM}}$ and $\mathrm{H}^{\mathrm{CHM}_{\max }}$, respectively, demonstrating that distributions did not significantly differ from a normal one. Since the two distributions were strictly correlated $(r=0.998, p<$ 0.001 ) a two-tailed paired $t$-test (Jayaraman 2000) was performed too, to determine if $\mathrm{H}^{\mathrm{CHM}}{ }_{\text {Max }}$ was significantly different from PDH ${ }^{\mathrm{CH}}$. A $t=-17.58(\mathrm{p}<0.001)$ was found indicating a significant difference between mean values of the two compared distributions, i.e., tree height values computed as $\mathrm{PDH}^{\mathrm{CHM}}$ are significantly different from those ordinarily computed in forestry $\left(\mathrm{H}^{\mathrm{CHM}}{ }_{\mathrm{Max}}\right.$ - Hyyppa et al. 2001, Andersen et al. 2006, Lisein et al. 2013).

Relative difference $(\Delta \mathrm{Hs})$ between $\mathrm{H}^{\mathrm{CHM}}{ }_{\text {max }}$ and $\mathrm{PDH}^{\mathrm{CHM}}$ was calculated for each tree and the correspondent cumulated frequency distribution generated. $\sigma_{z}{ }^{\mathrm{CHM}}$ value was
Fig. 4 - $\mathrm{H}^{\mathrm{CHM}}$ (left) and $\mathrm{PDH}^{\mathrm{CHM}}$ (right) frequency distributions computed considering all surveyed trees in study area.
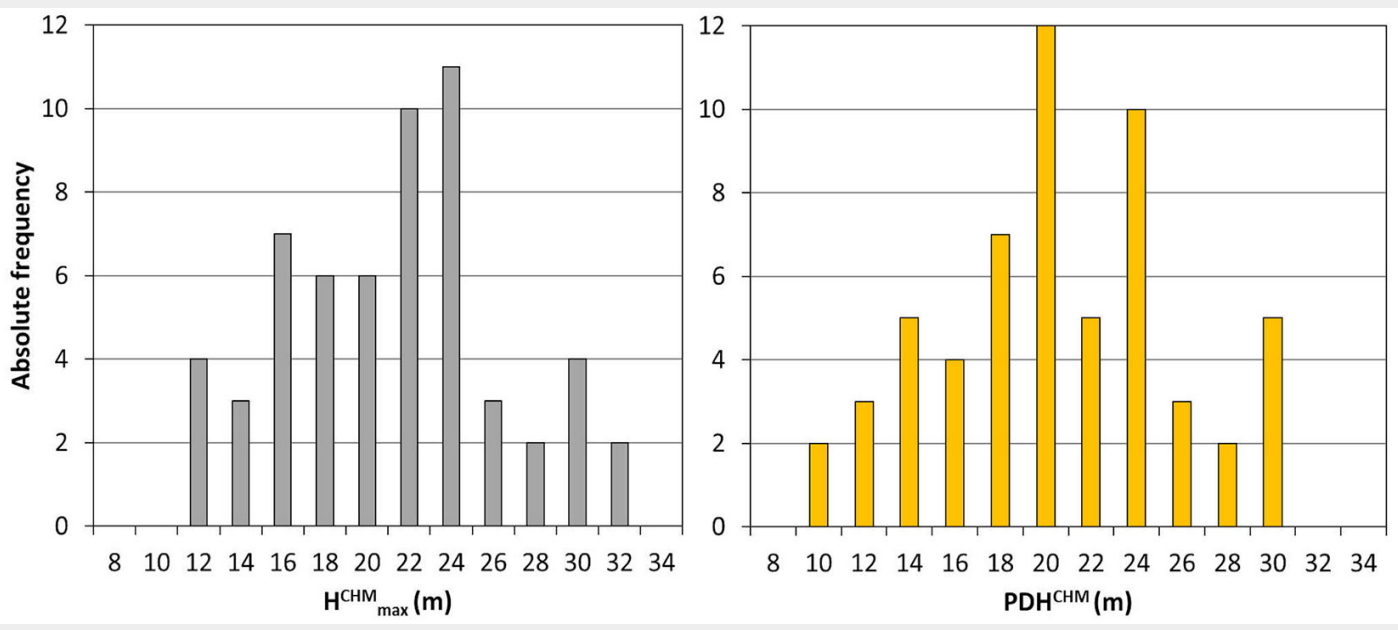
Fig. 5 - $\Delta \mathrm{Hs}$ cumulative distribution function and correspondent box-plot (min, Q1, median, Q3, max) computed with reference to all the trees in the study area. Red line shows CHM estimated accuracy $\left(\sigma_{z}{ }^{\mathrm{CHM}}\right)$

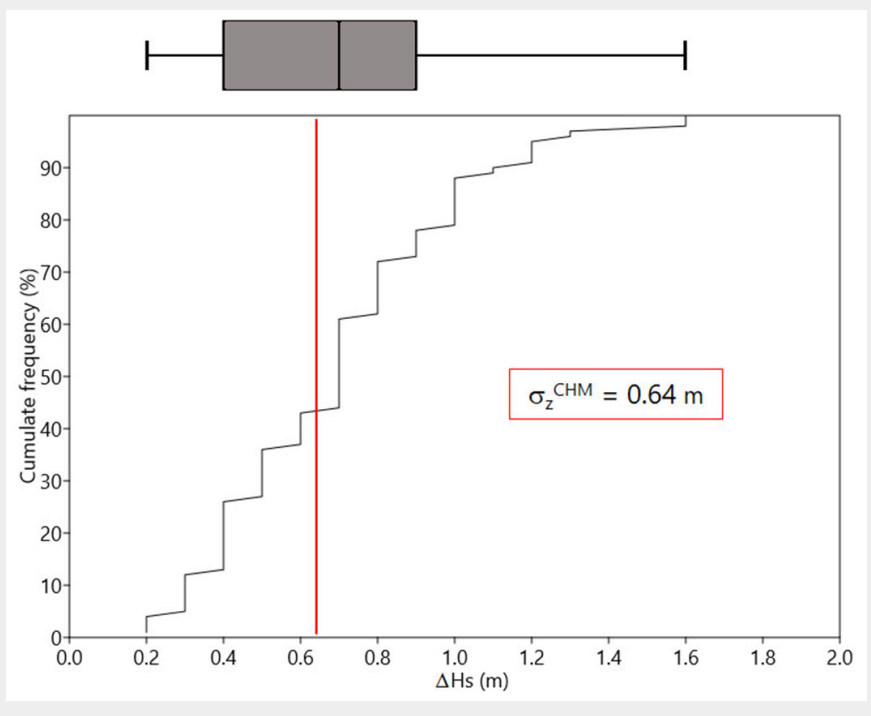

used as threshold to test if differences were significant or not (Fig. 5). The $57 \%$ of $\Delta \mathrm{Hs}$ resulted to be greater than $\sigma_{z}{ }^{\mathrm{CHM}}$ further demonstrating that tree height computed according to $\mathrm{PDH}^{\mathrm{CHM}}$ is significantly different from that computed with reference to $\mathrm{H}^{\mathrm{CHM}}$ max in more than a half of cases.

\section{Conclusions}

PHODAR will represent a potential tool for more suitable and accurate forest inventories in the next future. Nevertheless, it introduces new ambiguities (i.e., potential errors) during forest parameters measurement (e.g., tree height, stem volume, etc.). With special concerns about tree height measures, we propose an approach based on the new concept of PDH. The value of tree height measure is an operative convention that, depending on the context, can be interpreted differently. In this study a new definition of tree height is proposed that is thought to be an alternative to the ordinary approach based of local maxima, with the aim of minimizing the effect of apexes within the crown, which can significantly affect the final accuracy of estimates. In particular, the prevailing dendrometric height within the crown (PDH) involves the use of a correcting factor based on the frequency distribution function of the CHM height values contained within the crown perimeter. We found that the $95^{\text {th }}$ percentile of this distribution can be assumed as $\mathrm{PDH}^{\mathrm{CHM}}$. Results showed that differences between $\mathrm{PDH}^{\mathrm{CHM}}$ and $\mathrm{H}^{\mathrm{CHM}}$ $\operatorname{Max}$ (i.e., ordinary approach) were significant. Future developments are expected to be addressed to quantify the absolute accuracy of this method and the eventual improvements it can determine while estimating wood volume in forest stands with reference to different species.

\section{Acknowledgements}

We thank Dr. Martina Zucaro for the help in ground surveys, Dr. Claudio Rizzo for the RPAS flight, and La Mandria natural park technicians for the project support.

\section{References}

Andersen H-E, Reutebuch SE, McGaughey RJ (2006). A rigorous assessment of tree height measurements obtained using airborne lidar and conventional field methods. Canadian Journal of Remote Sensing 32: 355-366. - doi: 10.558 9/mo6-030

Bevington PR, Robinson DK (1974). Data reduction and error analysis for the physical sciences. McGraw-Hill, New York, USA, vol. 4, pp. 428.

Bond BJ (2000). Age-related changes in photosynthesis of woody plants. Trends in Plant Science 5: 349-353. - doi: 10.1016/S1360-1385(00)0 1691-5

Borgogno Mondino E, Fissore V, Lessio A, Motta $R$ (2016). Are the new gridded DSM/DTMs of the Piemonte Region (Italy) proper for forestry? A fast and simple approach for a posteriori metric assessment. iForest - Biogeosciences and Forestry 9: 901-909. - doi: 10.3832/ifor1992009

Borgogno Mondino E, Gajetti M (2017). Preliminary considerations about costs and potential market of remote sensing from UAV in the Italian viticulture context. European Journal of Remote Sensing 50: 310-319. - doi: 10.1080/227972 54.2017 .1328269

Bragg DC (2014). Accurately measuring the height of (real) forest trees. Journal of Forestry 112: 51-54. - doi: 10.5849/jof.13-065

Brovelli MA, Crespi M, Fratarcangeli F, Giannone $F$, Realini E (2008). Accuracy assessment of high resolution satellite imagery orientation by leave-one-out method. ISPRS Journal of Photogrammetry and Remote Sensing 63: 427-440. - doi: 10.1016/j.isprsjprs.2008.01.006

De Petris S, Berretti R, Sarvia F, Borgogno Mondino $E$ (2019). Precision arboriculture: a new approach to tree risk management based on geomatics tools. In: Proceedings of the Conference “SPIE Remote Sensing 2019". SPIE, Remote Sensing for Agriculture, Ecosystems, and $\mathrm{Hy}-$ drology 21: 111491G. - doi: 10.1117/12.2532778

Fritz A, Kattenborn T, Koch B (2013). UAV-based photogrammetric point clouds - tree stem mapping in open stands in comparison to terrestrial laser scanner point clouds. ISPRS - International Archives of the Photogrammetry, Remote Sensing and Spatial Information Sciences
XL-1/W 2: 141-146. - doi: 10.5194/isprsarchives-XL1-W2-141-2013

Hassaan O, Nasir AK, Roth H, Khan MF (2016). Precision forestry: trees counting in urban areas using visible imagery based on an unmanned aerial vehicle. IFAC-PapersOnLine 49: 16-21. - doi: 10.1016/j.ifacol.2016.10.004

Hyyppa J, Kelle O, Lehikoinen M, Inkinen M (2001). A segmentation-based method to retrieve stem volume estimates from 3-D tree height models produced by laser scanners. IEEE Transactions on Geoscience and Remote Sensing 39 (5): 969-975. - doi: 10.1109/36.921414

Isenburg M (2012). LAStools - efficient tools for LiDAR processing. Web site. [online] URL: http://www.cs.unc.edu/ isenburg/lastools/

Jakubowski M, Li W, Guo Q, Kelly M (2013). Delineating individual trees from LiDAR data: a comparison of vector-and raster-based segmentation approaches. Remote Sensing 5: 4163-4186. - doi: 10.3390/rs5094163

Jayaraman K (2000). A statistical manual for forestry research. Forestry research support programme for Asia and the pacific. FAO-UN Regional Office for Asia and the Pacific, Bangkok, Thailand, pp. 32-34.

Jayathunga S, Owari T, Tsuyuki S (2018). Evaluating the performance of photogrammetric products using fixed-wing UAV imagery over a mixed conifer-broadleaf forest: comparison with airborne laser scanning. Remote Sensing 10 (2): 187. - doi: 10.3390/rs10020187

Larsen DR, Hann DW, Stearns-Smith SC (1987). Accuracy and precision of the tangent method for measuring tree height. Western Journal of Applied Forestry 2: 26-28. - doi: 10.1093/wjaf/2. 1.26

Lisein J, Pierrot-Deseilligny $M$, Bonnet $S$, Lejeune P (2013). A Photogrammetric Workflow for the Creation of a forest canopy height model from small unmanned aerial system imagery. Forests 4: 922-944. - doi: 10.3390/f4040922

Monnet J-M, Mermin E, Chanussot J, Berger F (2010). Tree top detection using local maxima filtering: a parameter sensitivity analysis. In: Proceedings of the " $10^{\text {th }}$ International Conference on LiDAR Applications for Assessing Forest Ecosystems". Freiburg (Germany) 14-17 Sept 2010. Silvilaser, Freiburg, Germany, pp. 3-5. [online] URL: http://hal.archives-ouvertes.fr/ hal-00523245/

Nevalainen O, Honkavaara E, Tuominen S, Viljanen N, Hakala T, Yu X, Hyyppä J, Saari H, Pölönen I, Imai NN (2017). Individual tree detection and classification with UAV-based photogrammetric point clouds and hyperspectral imaging. Remote Sensing 9 (3): 185. - doi: 10.3390/rs903 0185

Ni W, Liu J, Zhang Z, Sun G, Yang A (2015). Evaluation of UAV-based forest inventory system compared with LiDAR data. In: Proceedings of the "2015 IEEE International Geoscience and Remote Sensing Symposium (IGARSS)". IEEE, Milan, Italy. - doi: 10.1109/IGARSS.2015.7326670 St-Onge B, Audet F-A, Bégin J (2015). Characterizing the height structure and composition of a boreal forest using an individual tree crown approach applied to photogrammetric point clouds. Forests 6: 3899-3922. - doi: $10.3390 / f 6$ 113899

Van Laar A, Akça A (2007). Forest mensuration 
( $2^{\text {nd }}$ edn), Springer, Dordrecht, Netherlands, pp. 47-54. [online] URL: http://books.google.com/ books?id=ybjdxL2IHOQC

Wallace L, Lucieer A, Watson C, Turner D (2012). Development of a UAV-LiDAR system with application to forest inventory. Remote Sensing 4: 1519-1543. - doi: 10.339o/rs4061519

Wallace L, Musk R, Lucieer A (2014). An assessment of the repeatability of automatic forest inventory metrics derived from UAV-borne laser scanning data. IEEE Transactions on Geo- science and Remote Sensing 52: 7160-7169. doi: 10.1109/TGRS.2014.2308208

Wang L, Gong P, Biging GS (2004). Individual tree-crown delineation and treetop detection in high-spatial-resolution aerial imagery. Photogrammetric Engineering and Remote Sensing 70:351-357. - doi: 10.14358/PERS.70.3.351

West PW (2009). Tree and forest measurement. Springer, Berlin, Germany, pp. 19-24. - doi: 10.10 07/978-3-319-14708-6

Yang J, He Y, Caspersen JP, Jones TA (2017). De- lineating individual tree crowns in an unevenaged, mixed broadleaf forest using multispectral watershed segmentation and multiscale fitting. IEEE Journal of Selected Topics in Applied Earth Observations and Remote Sensing 10: 1390-1401. - doi: 10.1109/JSTARS.2016.2638822 Zambarda A, Cerny M, Vopnka P (2010). Fieldmap - the new technology designed by IFER for the collection and processing of forest inventory data. Sherwood - Foreste ed Alberi Oggi 33-38. 